Volume 8, No. 7, July - August 2017

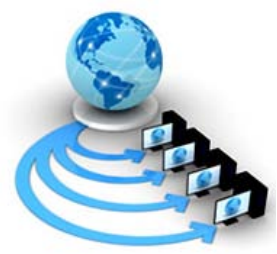

International Journal of Advanced Research in Computer Science

REVIEW PAPER

Available Online at www.ijarcs.info

\title{
CROP SIMULATION MODEL FOR MALWA REGION PUNJAB
}

\author{
Parmeet Kaur \\ Research Student, M. Tech. (CE), Department of Computer \\ Engineering, Punjabi University Patiala
}

\author{
Er. Sikander Singh Cheema \\ Assistant Professor, Department of Computer Engineering, \\ Punjabi University Patiala
}

\begin{abstract}
The Crop Simulation Models are used to estimate the crop production of a region by using various parameters like temperature, soil, weather and crop management etc. There are various models for the purpose of estimating crop production of various countries. As DSSAT model, that is developed and used by USA, has a modular design and it is a daily time step model that facilitates the evaluation and application of the crop models for different purposes. But our model is specifically designed for Malwa Region Punjab. It considers various parameters of soil and crop as input and then analyzes the result of estimation of crop yield by checking available weather and soil conditions of that particular area and use a suitable algorithm to estimate the future production of the crop.
\end{abstract}

Keywords: Crop model, soil, simulation, crop, productivity, diversification, weather.

\section{INTRODUCTION}

Agriculture is the main occupation for most of the people in Punjab. The production of crop greatly affects their income sources. It will be helpful for them to estimate crop production, for a particular soil and other conditions; before growing the actual crop. Crop Simulation Models are used for this purpose. Crop Simulation Models are used to estimate the production of a crop before actual growth of a crop. This estimation is based on some parameters like weather conditions, soil conditions, and choice of crop management practices [8]. The International Consortium for Agricultural Systems Applications (ICASA) plans to advance the development of crop models, so for this purpose they adopt modular approach. The models were designed as modules that one module is independent to the other, and for further development of the model a next module is can be added to it. The main features of this modular growth were: (1) modules should be independent of each other, that mean change in one module should not affect the other, (2) modules should be able to work with minimum number of inputs [1].

According to this modular growth, we have studied various models for various countries. DSSAT model (developed in USA) has a modular structure [9]. The main functions of DSSAT are like: (1) to estimate crop yield on the basis of weather, genetics, soil water, soil carbon, nitrogen and other management components, (2) it provides information about mono-crop production and crop rotations at any location where minimum inputs are provided, (3) helps to give idea of management of crop such as harvesting, cropping, irrigation dates estimates and it helps to easily compare forecasted data and actual yield [2].

CropSyst model is another model which is developed by Washington State University's Department of Biological Systems Engineering, United States. CropSyst is a multiyear, multi crop simulation model which consider daily time step. The CropSyst is linked to GIS software, a weather generator and other utility programs to calculate daily data and to make it user friendly. CropSyst simulates crop growth and various other factors like crop canopy (the above ground portion of plant community or crop, formed by the collection of individual plant crowns), soil water budget, soil-plant nitrogen budget, crop phenology (study of periodic plant and animal life cycle events), biomass production, residue production and decomposition etc. The main feature of this model is that it enables crop rotation [3]. APSIM (Agricultural Production Systems sIMulator) is one of the models that use modular structure. It has been developed by the Agricultural Production Systems Research Unit (APSRU) in Australia. It has three modules named as plant module, soil module and management module. It deals with biophysical processes and also considers wide range of crops, pastures and trees, soil processes like water balance, $\mathrm{N}$ and $\mathrm{P}$ transformations, soil $\mathrm{pH}$ and erosion etc. It is centered by a simulation engine that controls simulation processes and acts as a interface for various modules. It gives us output including the factors related to climate, genotype, soil and management [15]. This model manages all the processes and parameters that can affect the crop in any way like soil and water balance, erosion, soil $\mathrm{pH}$, soil organic matter and nitrogen, residues etc [4].

\section{OBJECTIVES}

Based on the above information, we come to know about various models and their functions. Now we have decided to develop a new model particularly for Malwa Region, Punjab. The newly designed model will be based on the crops that are grown in Malwa and the conditions of soil and weather of Punjab. The main objective of this study are defined as -

- $\quad$ Study of various crops that are produced in Malwa region and their soil specifications.

- Check for crop diversification for utilization of available resources.

- Estimate the crop production using the proposed model.

This study was done in three sections that are: Section 1 was the study of five crops of Malwa region (rice, wheat, 
sugarcane, maize, potato) and their soil requirements. Section 2 is to study various impacts of weather on crop growth and go for crop diversification for better income and to save soil and environment conditions. Section 3 was to design a new model to estimate production of given crops [12].

B.1. Study of various crops and their soil specifications

Here we have studied various crops that are grown in Malwa Region, Punjab. Although there are many crops of Malwa region, but we have considered only five crops and their duration and features of crops in Table 1. All these crops are mainly grown in Punjab. It can be defined as follows:-

1. Rice- Rice is the main crop of Punjab. India's 12 percent rice is grown in Punjab (http://water.columbia.edu). It is a kharif season crop and crop duration is about 120-140 days approximately. It is grown well in hot and moist climate. The requirements of temperature about $16^{\circ} \mathrm{C}-$ $27^{\circ} \mathrm{C}$ and rainfall $100 \mathrm{~cm}$ to $200 \mathrm{~cm}$ is ideal for rice growing. All other conditions are mentioned in the table.

\begin{tabular}{|c|c|c|c|c|c|c|c|c|}
\hline \multirow[t]{2}{*}{ S. No. } & \multirow[t]{2}{*}{ Name of Crop } & \multirow{2}{*}{$\begin{array}{l}\text { Crop } \\
\text { duration } \\
\text { ( in days ) }\end{array}$} & \multirow[t]{2}{*}{$\mathrm{pH}$ value } & \multirow{2}{*}{$\begin{array}{l}\text { Electrical } \\
\text { Conductivity } \\
\text { dS/m }\end{array}$} & \multirow{2}{*}{$\begin{array}{l}\text { Soil } \\
\text { Texture }\end{array}$} & \multicolumn{3}{|c|}{ Percentage } \\
\hline & & & & & & Sand & Slit & Clay \\
\hline 1. & Rice & $120-140$ & $6.2-6.7$ & 3.0 & Slit Clay & 10.7 & 47.2 & 42.1 \\
\hline 2. & Wheat & $60-150$ & $6.0-7.5$ & 6.0 & $\begin{array}{l}\text { Heavy } \\
\text { Loam }\end{array}$ & 12.5 & 49.6 & 43.5 \\
\hline 3. & Maize & $80-95$ & $6.0-7.5$ & 1.7 & Slit Loam & 32.8 & 29.0 & 38.2 \\
\hline 4. & Sugarcane & $480-540$ & $5.0-8.5$ & 1.7 & Light Clay & 33.0 & 30.2 & 30.8 \\
\hline 5. & Potato & $70-80$ & 5.8-6.5 & 1.5 & Clay Loam & 52.1 & 27.7 & 20.1 \\
\hline
\end{tabular}

Table 1 : Specifications of crops and soil

2. Wheat- Wheat is the main crop of Punjab. India's 20 percent rice is grown in Punjab (http://water.columbia.edu). It is a rabbi season crop and crop duration is about 60-150 days approximately. The initial weather required for wheat should be warm and moist and it should be sunny and dry in the end. The average temperature should be between $15.5^{\circ} \mathrm{C}$ $20^{\circ} \mathrm{C}$ and rainfall should be $30 \mathrm{~cm}-100 \mathrm{~cm}$ [14].

3. Maize- It is a kharif season crop and it is most widely grown in both tropical and warm temperature latitudes. The temperature required for maize should be between $18^{\circ} \mathrm{C}$ and $27^{\circ} \mathrm{C}$ during day and around $14^{\circ} \mathrm{C}$ during night and ideal rainfall for maize is $70 \mathrm{~cm}-80 \mathrm{~cm}$.

4. Sugarcane- It is a kharif season crop and it is considered as a tropic plant. It is a long duration crop having duration of about 480-540 days. The rainfall required for sugarcane is about $1100 \mathrm{~mm}-1500 \mathrm{~mm}$. It needs a long warm growing season and temperature varies between $32^{\circ}$ to $38^{\circ} \mathrm{C}$ depending on the growth stage of the crop.

5. Potato- It is a kharif season crop and it requires a cool climate, but it is adapted to wide range of climatic conditions. The required temperature for potato is $150^{\circ}$ to $250^{\circ} \mathrm{C}$. The rainfall required is $12 \mathrm{~mm}$. The time duration required for potato is about 70-80 days. [10]

B.2.Crop Diversification Study

As we come to know from the literature study and present conditions of Punjab region that weather plays an important role in growth of crops. The effects of climate change can be defined as follows:-

- It can affect the growth of the crop due to increase or decrease in the temperature of atmosphere or soil.

- The increased concentration of carbon dioxide can affect the natural growth of plant and can increase the green house effect.

- The changed climate also affects biophysical processes of crops that can be defined as photosynthesis, respiration, plant growth, reproduction and uptake of water from soil using roots of the crop [6].
There may be many causes of weather change. It also affects the properties of soil due to increased concentration of carbon dioxide or other gases due to rainfall. The changed properties of soil like lack in particular nutrition, soil erosion, improper content of nitrogen, carbon, phosphorous or potassium, can affect the crop growth. The effects of changed soil properties can be defined as follows:-

- It results in poor growth of crops.

- This type of soil may be useless for one type of crops.

- It may results in low yield and it will be less beneficial for the farmer.

There are a lot of ways to make soil perfect for crops that may include (a).extra addition of nutrition elements like carbon, phosphorous, nitrogen or potassium form outside, (b). by using crop rotation that means growing one type of crops for one time, and for next time use different crops.

This way is defined as 'Crop Diversification'. When the farmers grow same type of crops for years, for example wheat and rice, it results in lack of nutrition values of the soil. But they do not stop this rotation and keep on growing these crops because these and beneficial for them. But this can be avoided by using crop diversification. In it, we will check the results of production and our total benefit from crops for a particular region [5]. We are going to suggest a technique that can ensure the farmers that crop diversification is beneficial for them. In this technique, the following steps should be taken:-

1. Firstly, in a particular area that is Malwa region, the area is divided on the basis of soil and weather conditions i.e. fertile and less fertile.

2. We should check the crops that are suitable according to the properties of soil and weather. For example - rice requires an area which is hot and moist and it requires about $100 \mathrm{~cm}$ rainfalls and soil requirement is slit clay. So we will go for the area that has same properties as mentioned above for growing rice and similarly for other crops [11].

3. Then divide the field into three parts or make clusters. Grow various types of crops in it and observe their growth based on any crop model. The production of any 
crop in future can be calculated as weighted least square regression model. This model is defined for linear and non linear equations and gives precise and accurate results with a least chance of error. The error defined in this process is mostly constant so can be eliminated easily.

4. Then check the significance value for a particular crop. If significance is more that $1 \%$ then crop is worth growing but if it is less than $1 \%$ then the grown crop will not show satisfactory results.

Hence, this technique can be used to implement crop farming which is very important in these days and degradation of environment is happening gradually. So to improve the condition of water supply, environment conditions, soil properties and income of farmers, crop diversification is a good alternative.

B.3.Objectives of Proposed Model

The new model is proposed on the basis of existing models. We have studied existing crop simulation models and decided to design the similar one for Malwa region of Punjab state. In crop simulation models, various inputs are considered and output is given as production of a particular crop [7]. The need of the crop simulation model can be due to following reasons:-

- It helps to know the production of a crop, so farmers can grow the crop which one is beneficiary for them.
- It puts the trust of the farmers in the crop diversification as they come to know which soil will grow better in their soil.

The model is proposed on the basis of the input required by it and the output provided by it. Our proposed system can be divided into three modules as follows:-

1. Databases: This module includes databases such as crop, soil and weather that has the values of soil and weather corresponding to the crop grown.

2. Crop Model: It is the main program that accepts the inputs and gives outputs that are defined as applications. It required crop name in the crop database and time duration for which the crop is grown. The input for weather module are:

a. Maximum and minimum temperature.

b. Precipitation.

c. Maximum rainfall.

The input for soil module includes:

a. Required $\mathrm{pH}$ value for the crop.

b. Drainage and runoff coefficient.

c. Electrical conductivity.

d. Soil texture and required slit, clay and sand percentage. [9]

3. Output: It is defined as the crop production and may be crop diversification suggestions in some cases.

Databases

Applications/ Output

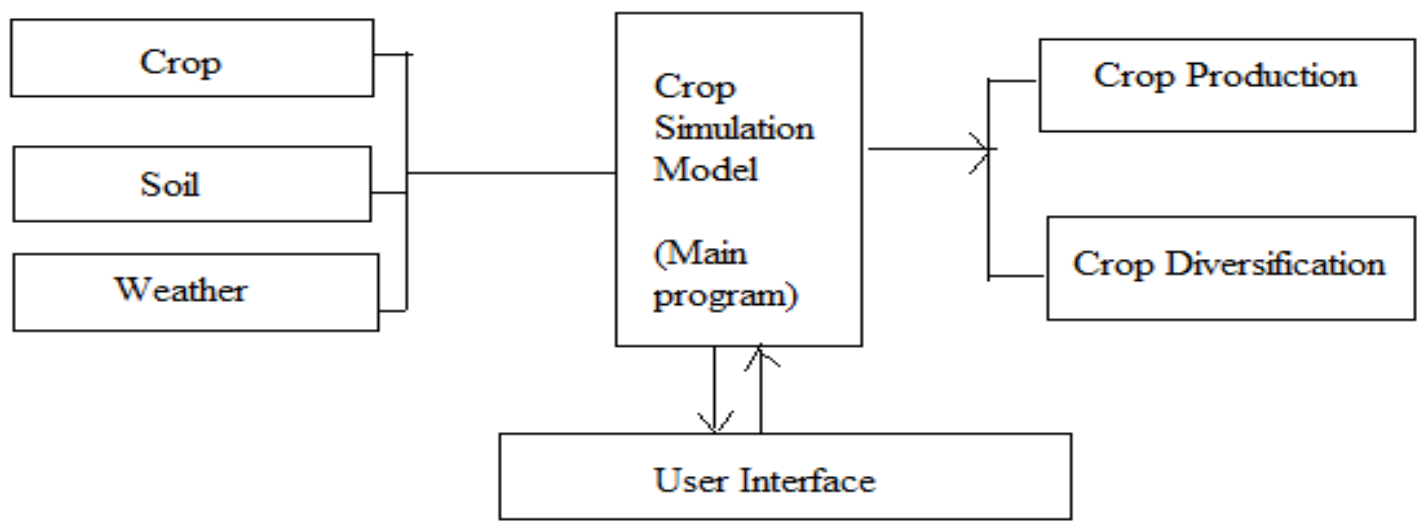

Figure 1 : Basic design of Crop Simulation Model

4. User interface: It will be an environment or interface that will deal with the user. It will accept user's inputs and will show required results to the user [13].

Future Scope: As we have proposed this model. So the future work includes the implementation of the model. Agriculture is necessary for humans because it gives them food to eat and it also fulfils many other needs of the human beings. So the future work includes the implementation of proposed model that will give output as production of a particular crop. It can also be extended by adding any other modules in it like crop management features, adding more crops and pest control management etc. The results of the proposed model will be compared with the existing models to check the accuracy of the system.

\section{REFERENCES}

[1]. J.W. Jones, B. K. (2001). Approaches to modular model development. Agricultural Systems , 421-443.

[2]. J.W. Jones, G. H. (2003). The DSSAT cropping system model. European Journal of Agronomy , 31

[3]. Claudio O. Stockle, M. D. (2003). CropSyst, a cropping systems simulation model. European Journal of Agronomy , 19.

[4]. B.A. Keating, P. C. (2003). An overview of APSIM, a model designed for farming systems simulation. European Journal of Agronomy, 267-288.

[5]. Nivedita Sharme, S. S. (2014). Agricultural Diversification in Indian Punjab: An Assessment of Government Intervention Through Contract Farming. Journal of Agricultural \& Food Information , 191-213. 
[6]. S.K. Jalota, G. S. (2006). Performance of CropSyst Model in Rice-Wheat Cropping System. Journal of Agricultural Physics 7.

[7]. Wu, R. C. (2013). Applications of DSSAT model to simulate weather growth in China. Canadian Center of Science and Education , 10.

[8]. Kazeem O. Rauff, R. B. (2015). A Review of Crop Growth Simulation Models As Tools for Agricultural Meterology. Scientific Research Publishing , 8.

[9]. Kelly R. Thorp, K. C. (2008). Methodology for the use of DSSAT models for precision agriculture decision support. Computers and Electronics in Agriculture , 11.

[10].Moritz Reckling, J.-M. H. (2015). A cropping system asssessment framework- Evaluating effects of introducing legumes into crop rotations . European Journal of Agronomy, 12.
[11].Benyamin Khoshnevisan, E. B. (2015). A clustering model based on an evolutionary algorithm for better energy use in crop production. CrossMark , 29.

[12]. Rojalin Tripathy, K. N. (2013). Forecasting wheat yield in Punjab state of India by combining crop simulation model WOFOST and remotely sensed inputs. Remote Sensing Letters , 19-28.

[13].Nawshaba Islam, P. M. (2012). An assessment of crop diversification in Bangladesh: a spatial analysis. Applied Economics Letters, 29-33.

[14].Ravi Kant Singh, J. S. (2011). Integrated assessment of diversification of rice-wheat cropping system in IndoGangetic plain. Archives of Agronomy and Soil Science , 489-506.

[15]. Athula Ginige, A. I. (2016). Digital Knowledge Ecosystem for achieving Sustainable Agriculture Production: A Case Study from Sri Lanka. IEEE International Conference on Data Science and Advanced Analytics, (p. 10). 